\section{Psychotherapy and Psychosomatics}

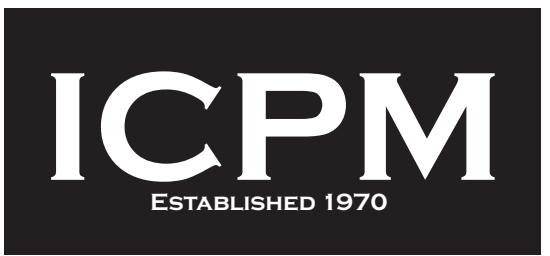

Published online: September 16, 2010

\title{
Advanced Training Workshop: Psychosomatic Assessment
}

On March 24-26, 2011, at Istituto Canossiano in Venice, Italy, there will be a workshop concerned with the novel techniques and strategies of psychosomatic assessment. The faculty includes Richard Balon (USA), Antonio Barbosa (Portugal), Giovanni Fava (Italy), Gabor Keitner (USA), Dennis Linder (Italy), Chiara Rafanelli (Italy), Tom Sensky (UK), Nicoletta Sonino (Italy), Tom Wise (USA) and Jesse Wright (USA). The faculty will share with the participants how psychosomatic assessment actually takes place by discussing clinical cases and the use of role playing. At the end of the workshop the participant will be able to use the new psychosomatic approach in his/her clinical practice, to enhance clinical effectiveness and to be aware of new treatment opportunities.

The workshop is aimed at physicians or psychologists, with special reference to those who have already achieved or wish to get the title of Psychosomatic Specialist by the International College of Psychosomatic Medicine.

Those who intend to attend should contact the Scientific Secretary, Elena Tomba, PhD, Department of Psychology, University of Bologna, Viale Berti Pichat 5, IT-40127 Bologna, Italy, Tel. +39 051209 1823, Fax +39 051243 086, E-Mail elena.tomba@unibo.it. 